\title{
Life course research: new opportunities for establishing social and biological plausibility
}

\author{
Michelle Kelly-Irving $\cdot$ Silke Tophoven $\cdot$ David Blane
}

Published online: 17 May 2015

(C) Swiss School of Public Health 2015

Life course research on health and disease has reached a new stage in exploring the social-to-biological transition. Large longitudinal datasets containing sociodemographic and socioeconomic characteristics, self-reported health assessments, psychological and biological data are coming into maturation and being made available to researchers. Some examples are the Survey of Health, Ageing and Retirement in Europe (SHARE), the UK Household longitudinal study (Understanding Society), The Longitudinal Aging Study Amsterdam (LASA), and linked registry data sets (particularly in Scandinavia). Consequently, questions around how environmental factors (in the broadest sense

\footnotetext{
Michelle Kelly-Irving is a social epidemiologist working for the French institute for health and medical research (INSERM). She is based at a research unit in Toulouse, in the South West of France and her main research focus is on the social determinants of health inequalities from early life onwards.

Silke Tophoven is a sociologist and research associate at the Institute for Employment Research in Nuremberg, Germany. She is interested in research on the relationship between work and health, with a special focus on women and ageing societies.

David Blane has a background in medicine and sociology. He is professor emeritus of Imperial College London and professorial research associate of University College London. His research interests include social class differences in mortality, life course studies and social gerontology.
}

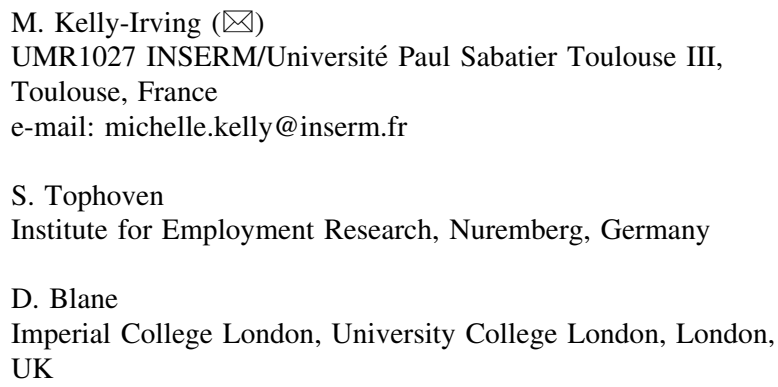

including social, psychosocial, behavioural, physical, etc.) lead to biological alterations over time can now be investigated on a wider scale, and in a variety of contexts and disciplines. Such work might also lead to a better understanding of the social structure of such social-to-biological mechanisms across the life course.

The field of life course research is interdisciplinary by construction, stemming from different traditions. Since the 1990s, life course research on health topics developed in parallel within the fields of demography, such as in Wunch et al.'s (1996) work on unfavourable life course states and mortality; in epidemiology, where the importance of childhood circumstances for future health was highlighted by Mann et al. (1992); and in sociology via pivotal research on intergenerational social mobility and transmission (Erikson and Goldthorpe 1992, 2002). An interdisciplinary field of life course research has emerged from collaborations between these disciplines and others (Richter and Blane 2013).

Given these strong traditions, life course research is well placed to establish both social and biological plausibility in hypothesis testing (Mayer 2009). While the literature has now established the associations between measures of the socioeconomic environment and subsequent morbidity and mortality, the specific pathways along which these associations are likely to operate need to be disentangled. A growing body of research hypotheses on the specific pathways that may operate between different environmental factors and biological embodiment can be identified and tested, informing deductive methods and the rejection of hypotheses or formulation of new ones (Blane et al. 2013).

Recent examples of this type of research can be found in a previous issue of this journal. Hypotheses were put forward on central-nervous-system-mediated (or psychosocial) mechanisms around the development of cancers from early 
life (Kelly-Irving et al. 2013), or the material versus educational pathways implicated in the development of chronic pathologies in Kenya (Ploubidis et al. 2013). Currently available biological data allow this type of hypothesis to be explored. For example, Sundin et al. (2014) recently identified the role of inflammatory markers as well as socioeconomic indicators during adolescence in the development of chronic kidney disease up to 40 years later. Bartley et al. (2011) also highlighted a tracking of financial adversity from childhood towards respiratory disease in midlife.

These lines of investigation are moving aetiological research into health and disease forward, but also offer the possibility of exploring new definitions of health combining different types of health measures: questionnaire tools, self-reported health measures, registry data, biometric health measures and biomarkers. The increased potential of combining versatile measures requires stronger interdisciplinary collaborations bringing together research findings from social and biomedical sciences. Among the available data, epigenetic information allows us to explore mechanisms of environment-driven gene expression; however, many other biological indicators are now available allowing for a biological systems approach (Barabasi et al. 2011) in understanding how populations interact with their environments.

Studying the social-to-biological transition offers opportunities in the field of public health to identify and act upon modifiable factors within our environments that may improve health for populations. To do so involves pursuing interdisciplinary research taking whole systems, both social and biological, into account. To this end, the authors have initiated an Interdisciplinary Health Research working group within the Society for Longitudinal and Life Course Studies. The aim of the group is to structure and facilitate health-related research across disciplinary boundaries and promote open access datasets.

\section{References}

Barabasi A-L, Gulbahce N, Loscalzo J (2011) Network medicine: a network-based approach to human disease. Nat Rev Genet 12(1):56-68. doi:10.1038/nrg2918

Bartley M, Kelly Y, Sacker A (2011) Early life financial adversity and respiratory function in midlife: a prospective birth cohort study. Am J Epidemiol. doi:10.1093/aje/kwr284

Blane D, Kelly-Irving M, Errico A, Bartley M, Montgomery S (2013) Social-biological transitions: how does the social become biological? Longitud Life Course Stud Int J 4(2):136-146. doi:10.14301/llcs.v4i2.236

Erikson R, Goldthorpe J (1992) The Constant Flux: class mobility in industrial societies. Clarendon, Oxford

Erikson R, Goldthorpe JH (2002) Intergenerational inequality: a sociological perspective. J Econ Perspect 16(3):31-44. doi:10. $2307 / 3216948$

Kelly-Irving M, Mabile L, Grosclaude P, Lang T, Delpierre C (2013) The embodiment of adverse childhood experiences and cancer development: potential biological mechanisms and pathways across the life course. Int J Public Health 58(1):3-11. doi:10. 1007/s00038-012-0370-0

Mann SL, Wadsworth ME, Colley JR (1992) Accumulation of factors influencing respiratory illness in members of a national birth cohort and their offspring. J Epidemiol Community Health 46(3):286-292

Mayer KU (2009) New directions in life course research. Annu Rev Sociol 35:413-433. doi:10.1146/annurev.soc.34.040507.134619

Ploubidis G, Mathenge W, De Stavola B, Grundy E, Foster A, Kuper H (2013) Socioeconomic position and later life prevalence of hypertension, diabetes and visual impairment in Nakuru, Kenya. Int J Public Health 58(1):133-141. doi:10.1007/s00038-012-0389-2

Richter M, Blane D (2013) The life course: challenges and opportunities for public health research. Int J Public Health 58(1):1-2. doi:10.1007/s00038-012-0436-z

Sundin P-O, Udumyan R, Sjöström P, Montgomery S (2014) Predictors in adolescence of ESRD in middle-aged men. Am J Kidney Dis 64(5):723-729. doi:10.1053/j.ajkd.2014.06.019

Wunsch G, Duchêne J, Thiltgès E, Salhi M (1996) Socio-economic differences in mortality. A life course approach. Eur J Popul 12(2):167-185. doi:10.1007/bf01797082 